\title{
Non-invasive respiratory support and preterm infants: The crucial role of nurse management
}

\author{
Gianluca Lista, Francesca Castoldi, Paola Fontana, Mariella Frongia, Petojevic Mirjana, Laura \\ Tansini, Valentina Pivetti \\ NICU "Vittore Buzzi" Children's Hospital, ICP, Milan, Italy \\ Correspondence: Gianluca Lista, MD. Address: NICU "Vittore Buzzi" Children's Hospital, ICP, Milan, Italy. Telephone: \\ 39-025-799-5341. Email: g.lista@icp.mi.it.
}

Received: December 27, 2012

Accepted: March 5, 2013

Online Published: May 22, 2013

DOI : 10.5430/jnep.v3n12p111

URL: http://dx.doi.org/10.5430/jnep.v3n12p111

\begin{abstract}
Premature delivery is often a failure of transition to create an early Functional Residual Capacity (FRC) and therefore preterm infants frequently need a respiratory support. To reduce the occurrence or severity of respiratory distress, neonatologists have to plan an optimal respiratory strategy from the first breath and within the "working-team" the nurses play a crucial role. Since duration of mechanical ventilation via the ET seems related to Bronchopulmonary Dysplasia (BPD), clinicians are increasingly using non invasive respiratory supports (e.g. n-CPAP and Non-Invasive VentilationNIV) to try to protect the preterm infant's lungs. Nurses are essential fundamental in choosing the best fitted devices and interfaces (e.g. hat, prongs), in protecting skin from infections, in taking a continuous care of the neonate to avoid nasal trauma, in maintaining and protecting parental bonding. The success of non-invasive respiratory support improves with staff experience and it is recognized that there is an urgent need for continuous education of nursing staff in preventing failure of non-invasive respiratory support.
\end{abstract}

\section{Key words}

Nurse, Non-invasive respiratory support, Preterm infants

\section{Introduction}

Premature delivery is often a failure of transition to create an early Functional Residual Capacity (FRC). In fact many very early preterm babies, even if spontaneously breathing at birth, frequently need a respiratory support because of multiple gaps (i.e. poor respiratory diaphragm muscle strength, poor inspiratory pressure, high chest wall compliance, low lung compliance due to surfactant deficiency, neurological impairment and inefficient fluid clearance, etc) ${ }^{[1]}$. To reduce the occurrence or severity of respiratory distress, neonatologists have to plan an optimal respiratory strategy from the first breath and the nurses play a crucial role within the "working-team".

At birth, in the delivery room, nurses can help physicians in many ways: by preparing the infant warmer with the adequate temperature level or covering the newly-born in plastic wrapping (if very low birth weight -VLBW- infants, $<1.5 \mathrm{Kg}$ ) to avoid loss of body-temperature that may worsen the respiratory distress; by suctioning the newly born with obvious obstruction to spontaneous breathing or if positive pressure ventilation (PPV) is required; by setting the humidification and blender devices for eventual oxygen supplementation guided by references value of pre-ductal saturation monitored 
by pulse oxymeter ${ }^{[2]}$. Nurses may also help the neonatologist in choosing the appropriate size facial-mask to perform PPV. Nurses and physicians would subsequently act together to achieve an early FRC by applying a continuous positive airway pressure (CPAP), or stepwise increments of positive end-expiratory pressure (PEEP); or using a sustained lung inflation (SLI), followed by CPAP ${ }^{[3,4]}$. The T-piece resuscitator should be available in the delivery room and adequately set for the occurrence. Even the preterm baby is able to maintain a normal gas-exchange with a spontaneous breathing or only assisted with a non-invasive support if the fetal-neonatal transition has been completed in the delivery room reaching an early and adequate FRC by a lung recruitment maneuver.

\section{Respiratory management in the context of neonatal care}

Since prolonged length of mechanical ventilation via the ET seems related to Bronchopulmonary Dysplasia (BPD) ${ }^{[5,6]}$, clinicians are increasingly using non-invasive respiratory supports to try to protect the preterm infant's lungs ${ }^{[7,8]}$. In the NICU the utilization of non invasive modality as unique respiratory support in the management of RDS has increased in the last years (see Figure 1). Between the numerous non invasive modalities, the widespread used is nasal-CPAP (N-CPAP), introduced by Gregory in 1971 for the treatment of neonatal RDS ${ }^{[9]}$ and initially delivered via an endotracheal tube but subsequently with more efficient interfaces is now widespread used. N-CPAP supports the breathing of preterm infant by splinting the upper airways and therefore reducing obstruction and apnea ${ }^{[10]}$; moreover N-CPAP reduces thoraco-abdominal asynchrony so maintaining lung volume by stabilization of the chest wall compliance and of the alveoli, which are prone to collapse due to surfactant deficiency in course of RDS ${ }^{[11]}$. When the physicians decide to support the spontaneously breathing baby by a "continuous distending pressure" from the delivery room, this respiratory support has to be maintained during the transport to the NICU in an incubator with apposite device to deliver CPAP (see Figure 2), in order to preserve the lung volume.
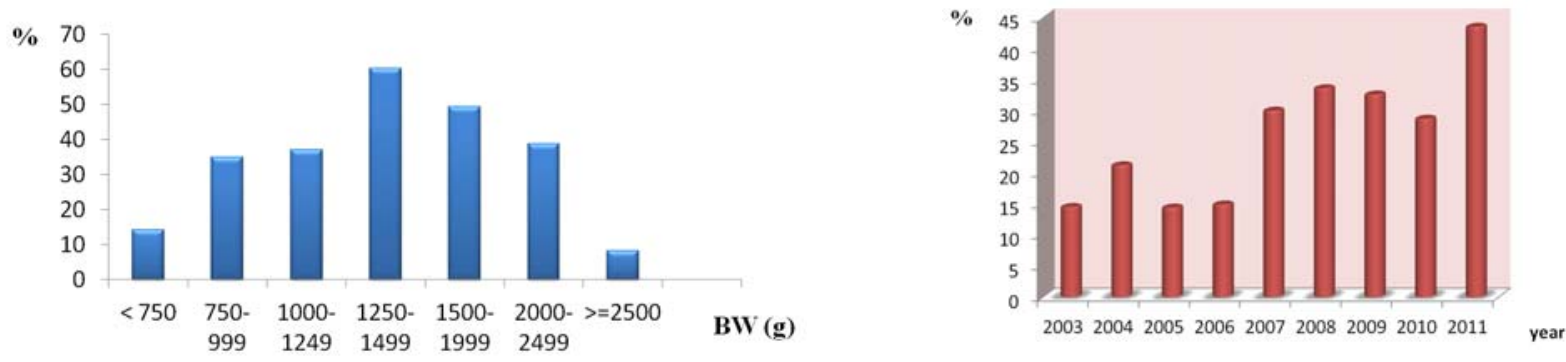

Figure 1. Percentage of preterm infants in exclusive non invasive respiratory support to manage RDS, according to birth weight and different years (n 913 infants admitted to "V.Buzzi" Children's Hospital, from 2003 and 2011 year).

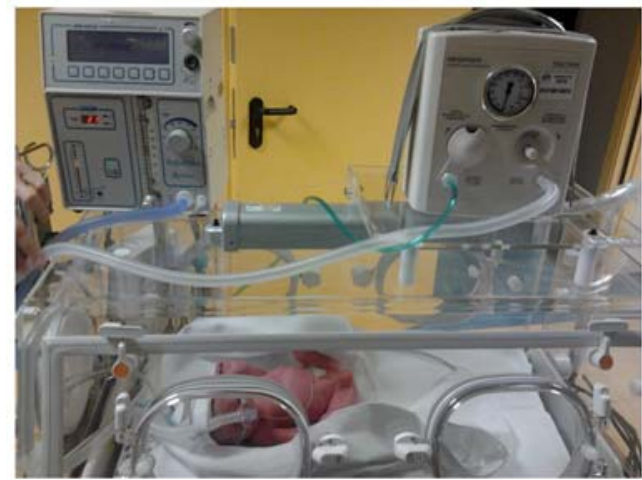

Figure 2. Incubator dedicated to the transport from the delivery room to the NICU, with NCPAP and T-Piece devices.

N-CPAP can be delivered by different devices (Bubble-CPAP, ventilator CPAP, and variable flow CPAP), and with numerous interfaces (nasopharyngeal tube, single nasal prong, binasal prongs, masks) ${ }^{[7]}$. The success of the N-CPAP not 
only depends from the underlying disease, but many times from both the infant's tolerance of interface and from nurse experience. N-CPAP is a valid alternative to mechanical ventilation in the management of respiratory distress of the preterm infants ${ }^{[12-15]}$, but only with the crucial role of nurses in this respiratory approach.

Nurses are essential fundamental in choosing the best fitted devices and interfaces (e.g. hat, prongs): the success of N-CPAP generally improves with staff experience ${ }^{[16,17]}$ and it is recognized that there is an urgent need for continuous education of nursing staff in preventing N-CPAP failure ${ }^{[18]}$. The required nursing care of preterm infant in non-invasive support is without any doubt increased and needs a specific organization and careful following of updated guidelines and protocols.

In a tertiary level NICU, the adequate beds ratio per registered nurse is determinant, and it depends on the different time needed by the nurses to take care of infants in ventilator support ${ }^{[19]}$. It has been demonstrated that babies on N-CPAP in the first days of life (e.g. acute phase of RDS) demand the same attention than those on mechanical ventilation; in conclusion the Authors suggest that one nurse should take care for one mechanically ventilated infant and one and half babies (maximum 2) on N-CPAP ${ }^{[20]}$.

Nurses have to complete the appropriate physical assessment and give continuous care of the neonate to avoid nasal trauma. The first sign of nasal trauma is redness and excoriation of the nostrils and can progress to necrosis of the columella and nasal septum requiring surgery ${ }^{[21,22]}$. Sometimes the available devices are too rigid, oversized or too heavy for tiny "premies", therefore appropriate hats and prongs have to be chosen and adjusted accurately to avoid pressure on the face and on the columella. The skin can be protected with hydrocolloid bands to avoid local infections that may cause dangerous sepsis. Periodic skin massage around the nares, allowing physiological vascularization, and a temporary use of nose mask, may help to prevent skin breakdown. Glamorgan Scale can be used to rate the pressure ulcer risk of pediatric population, even if this assessment scale is not always able to make clear distinctions in a low-risk setting ${ }^{[23,24]}$.

A systematic check of the prongs position can reduce the risk of lung hyperinflation (till airleak) due to higher level of CPAP from those ordered by the physician. Systematic checks also decrease the risk of lung derecruitment due to prongs dislocation which results in low CPAP levels. Excessive levels of CPAP increases intrathoracic pressure which may depress cardiac output (reduced pre-load due to obstructed venous return; direct effect on myocardial contractility).

NICUs tend to be noisy places and N-CPAP at high flow rates may generate over $100 \mathrm{~dB}$ in the post nasal spaces ${ }^{[25]}$ with the potential risk of neurosensory damage in cases of prolonged utilization and of sleeping difficulties for these infants during hospitalization.

N-CPAP does not improve ventilation for all preterm infants and is not efficacious in infants with poor respiratory effort. In these cases the use of a bi-level CPAP or "non-invasive ventilation" (NIV) through nasal devices can be useful in preterm infants both in triggered (N-SIMV/N-SIPPV) and in non- synchronized modality (N-IMV, N-IPPV, N-PSV) ${ }^{[1]}$.

When a nasopharyngeal tube is used to deliver N-CPAP or NIV (the tube is usually inserted $5 \mathrm{~cm}$ in nasopharynx), nurses have to remove secretions from the lumen to allow gas flow passage. Moreover, delicate suctioning of the nose, mouth and pharynx may be necessary to clean the upper airways from the excessive salivation (scialorrea).

The increased transpulmonary pressure produced by NIV may increase the risk of lung overinflation; therefore the nurses have to strictly monitor these babies $\left(\mathrm{SpO}_{2}\right.$, heart rate, thoracic asymmetry, transcutaneous $\mathrm{pO}_{2}$ and $\left.\mathrm{pCO}_{2}\right)$ in cooperation with the physician to avoid occurrence of airleak or to perform an immediate pleural drainage if necessary.

Minimal handling, wrapping (see Figure 3), neonatal individualized development care/assessment program, kangaroo care and breast feeding involving mother of the preterm babies, are very important to reduce negative stimulation of the infants in NIV and to reduce the need of pharmacological pain management ${ }^{[8]}$. It has been demonstrated that iatrogenic pain is a 
serious problem (particularly for ELBW infants born $<28 \mathrm{wks}$ ) ${ }^{[26]}$ with negative effects on neurological development and with the risk of agitation and of influence on cerebral hemodynamics ${ }^{[27]}$. For this reason it may be useful to reduce the number of procedures (e.g. manipulation on the CPAP prongs) especially in course of respiratory support and to use simple and effective pain-relief methods such as non-nutritive sucking or glucose solution (e.g. $2 \mathrm{ml}$ of $25 \%$ glucose solution through a syringe) ${ }^{[28,29]}$. However when non-pharmacological intervention is not efficient, the use of opioids (e.g. bolus dose of fentanyl or morphine i.v.) is allowed. Nurses (at least each turn of daily job) have to assess and register pain state of the infants in respiratory support in order to help physicians to prescribe pharmacological pain management. A pacifier will be offered to the infant in NIV, especially all infants needing high pressure levels for lung volume recruitment in the acute phase of RDS. Not only as non-pharmacological management of pain, but also to reduce the leak of the "continuous distending pressure" during CPAP from the mouth. An orogastric tube must be positioned for gastric detention to avoid gastrointestinal distention or perforation.
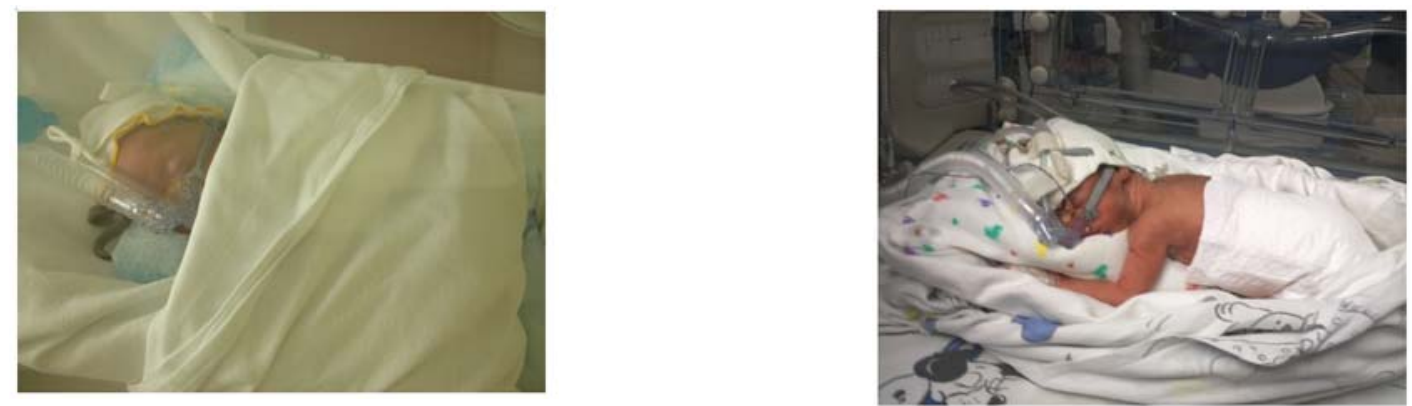

Figure 3. Wrapping and positioning of infants during non invasive respiratory support

\section{Conclusions}

We suggest Each NICU should create nursing care guidelines for neonates receiving NIV. This will reduce the risk of side effects and failure of this respiratory assistance modality. Moreover a continuous educational program of nursing staff for NIV management has to be planned in all the NICUs.

\section{Acknowledgements}

The authors would like to thank the neonatal nurse staff at V. Buzzi Children's Hospital for their support and skilled care of our patients.

\section{References}

[1] St Clair C, Norwitz ER, Woensdregt K, Cackovic M, Shaw JA, Malkus H et al. The probability of neonatal respiratory distress syndrome as a function of gestational age and lecithin/sphingomyelin ratio. Am J Perinatol. 2008 Sep; 25(8): $473-80$. PMid:18773379 http://dx.doi.org/10.1055/s-0028-1085066

[2] Kattwinkel J, Perlman JM, Aziz K, Colby C, Fairchild K, Gallagher J et al. Pediatrics. 2010 Nov; 126(5): e1400-13. PMid:20956432 http://dx.doi.org/10.1542/peds.2010-2972E

[3] te Pas AB, Walther FJ. A randomized, controlled trial of delivery-room respiratory management in very preterm infants. Pediatrics. 2007 Aug; 120(2): 322-9. http://dx.doi.org/10.1542/peds.2010-2972E http://dx.doi.org/10.1542/peds.2007-0114

[4] Lista G, Fontana P, Castoldi F, Cavigioli F, Dani C. Does sustained lung inflation at birth improve outcome of preterm infants at risk for respiratory distress syndrome? Neonatology. 2011; 99(1): 45-50. PMid:20616570 http://dx.doi.org/10.1159/000298312

[5] Stroustrup A, Trasande L. Epidemiological characteristics and resource use in neonates with bronchopulmonary dysplasia: 1993-2006. Pediatrics. 2010 Aug; 126(2): 291-7. PMid:20643728 http://dx.doi.org/10.1542/peds.2009-3456

[6] Gagliardi L, Bellù R, Lista G, Zanini R ; the Network Neonatale Lombardo Study Group. Do differences in delivery room intubation explain different rates of bronchopulmonary dysplasia between hospitals? Arch Dis Child Fetal Neonatal Ed. 2011 Jan; 96(1): F30-5. PMid:20659938 http://dx.doi.org/10.1136/adc.2010.183905 
[7] Peter G. Davis, Colin J. Morley, Louise S. Owen. Non-invasive respiratory support of preterm neonates with respiratory distress: Continuous positive airway pressure and nasal intermittent positive pressure ventilation. Seminars in Fetal \& Neonatal Medicine. 2009; 14: 14-20. PMid:18835546 http://dx.doi.org/10.1016/j.siny.2008.08.003

[8] Verder H, Nasal CPAP has become an indispensable part of the primary treatment of newborns with respiratory distress syndrome. Acta Paediatr. 2007; 96 (4): 482-484. PMid:17391463 http://dx.doi.org/10.1111/j.1651-2227.2007.00263.x

[9] Gregory GA, Kitterman JA, Phibbs RH, Tooley WH, Hamilton WK. Treatment of the idiopathic respiratory-distress syndrome with continuous positive airway pressure. N Engl J Med. 1971; 284: 1333-40. PMid:4930602 http://dx.doi.org/10.1056/NEJM197106172842401

[10] Miller MJ, DiFiore JM, Strohl KP, Martin RJ. Effects of nasal CPAP on supraglottic and total pulmonary resistance in preterm infants. J Appl Physiol. 1990; 68: 141-6. PMid:2179206

[11] Bancalari E, Claure N. Non-invasive ventilation of the preterm infant. Early Human Development. 2008; 84: 815-819. PMid:18824314 http://dx.doi.org/10.1016/j.earlhumdev.2008.09.010

[12] Sandri F, Plavka R, Ancora G, Simeoni U, Stranak Z, Martinelli S et al. Prophylactic or early selective surfactant combined with n-CPAP in very preterm infants. Pediatrics. 2010; 125: e1402-e1409. PMid:20439601 http://dx.doi.org/10.1542/peds.2009-2131

[13] Morley CJ, Davis PG, Doyle LW, Brion LP, Hascoet JM, Carlin JB et al. Nasal CPAP or intubation at birth for very preterm infants.NEJM. 2008; 358: 700-8. PMid:18272893 http://dx.doi.org/10.1056/NEJMoa072788

[14] Finer NN, Carlo WA, Walsh MC, Rich W, Gantz MG, Laptook AR et al. Early CPAP versus surfactant in extremely preterm infants. NEJM. 2010; 362: 1970-9. PMid:20472939 http://dx.doi.org/10.1056/NEJMoa0911783

[15] Dunn MS, Kaempf J, de Klerk A, de Klerk R, Reilly M, Howard D et al. Randomized trial comparing 3 approaches to the initial respiratory management of preterm neonates. Pediatrics. 2011; 128(5): e1069-e1076. PMid:22025591 http://dx.doi.org/10.1542/peds.2010-3848

[16] Aly H, Massaro AN, Patel K, El-Mohandes AA. Is it safer to intubate premature infants in the delivery room? Pediatrics. 2005; 115(6): 1660-1665. PMid:15930230 http://dx.doi.org/10.1542/peds.2004-2493

[17] Kribs A. Is it safer to intubate premature infants in the delivery room? Pediatrics. 2006; 117(5): 1858-9. PMid:16651355 http://dx.doi.org/10.1542/peds.2005-3210

[18] Jerzy Jerzy Szczapa, Janusz Świetliński, Klaudiusz Bober, Ewa Musialik-Świetlińska, Michał Bociański, Iwona DąbrowskaWójciak et al. The non invasive respiratory support programme with the infant flow method - outcomes of the first stage of programme application in newborns in Poland. Med Sci Monit. 2004; 10( Suppl 2): 7-13.

[19] Morcillo Sopena F, Gutiérrez Laso A, Castillo Salinas F, Elorza Fernández D, Gresa Muñoz M, Fernández Lorenzo JR et al. Respiratory care in neonatal intensive care units. Situation in the year. 2005. An Pediatr (Barc). $2009 ; 70$ (2): 137-42. PMid:19217569 http://dx.doi.org/10.1016/j.anpedi.2008.08.003

[20] DWA Milligan, P Carruthers, B Mackley, MP Ward Platt, Y Collingwood, L Wooler et al. Nursing workload in UK tertiary neonatal units. Arch Dis Child/ 2008; 93: 1059-1064. PMid:18591182 http://dx.doi.org/10.1136/adc.2008.142232

[21] McCoskey L. Nursing Care Guidelines for prevention of nasal breakdown in neonates receiving nasal CPAP. Adv Neonatal Care/ 2008; 8(2): 116-24. PMid:18418209 http://dx.doi.org/10.1097/01.ANC.0000317260.99072.ae

[22] Jatana KR, Oplatek A, Stein M, Phillips G, Kang DR, Elmaraghy CA. Effects of nasal continuous positive airway pressure and cannula use in the neonatal intensive care unit setting. Head Neck Surg. 2010; 136(3): 3287-3291.

[23] Kottner J, Schoer F, Tannen A. Evaluation of the Glamorgan scale in a pediatric intensive care unit: agreement and reliability. PFLEGE. 2012; 25(6): 459-467

[24] Kottner J, Kenzler M, Wilborn D. Interatter agreement, reliability and validity of the Glamorgan pediatric pressure ulcer risk assessment. J Clin Nutr 2012 Nov 5. http://dx.doi.org/10.1111/joch.12025 (epub ahead print)

[25] Surenthiran SS, Wilbraham K, May J, Chant T, Emmerson AJ, Newton VE. Noise levels within the ear and post-nasal space in neonates in intensive care. Arch Dis Child Fetal Neonatal ed. 2003; 88(4): F 315-8

[26] Cignacco E, Hamers J, van Lingen RA, Stoffel L, Büchi S, Müller R et al. Neonatal procedural pain exposure and pain management in ventilated preterm infants during the first 14 days of life. Swiss Med Wkly. 2009; 139(15-16): 226-232

[27] Milan A, Freato F, Vanzo V, Chiandetti L, Zaramella P. Influence of ventilation mode on neonatal cerebral blood flow and volume. Early Human Development. 2009; 85: 415-419. PMid:19217223 http://dx.doi.org/10.1016/j.earlhumdev.2009.01.008

[28] Liu MF, Lin KC, Chou YH, Lee TY. Using non-nutritive sucking and oral glucose solution with neonates to relieve pain: a randomised controlled trial. J Clin Nurse. 2010; 19(11-12): 1604-1611. PMid:20384669 http://dx.doi.org/10.1111/j.1365-2702.2009.03014.x

[29] Liaw JJ, Yang L, Ti Y, Blackburn ST, Chang YC, Sun LW. Non-nutritive sucking relieves pain for preterm infants during heel stick procedures in Taiwan. J Clin Nurse. 2010; 19(19-20): 2741-2751. PMid:20846224 http://dx.doi.org/10.1111/j.1365-2702.2010.03300.x 